\title{
Australia is 'free to choose' economic growth and falling environmental pressures
}

Steve Hatfield-Dodds*, Heinz Schandl, Philip D. Adams, Timothy M. Baynes, Thomas S. Brinsmead, Brett A. Bryan, Francis H. S. Chiew, Paul W. Graham, Mike Grundy, Tom Harwood, Rebecca McCallum, Rod McCrea, Lisa E. McKellar, David Newth, Martin Nolan, Ian Prosser \& Alex Wonhas

\section{PAPER ABSTRACT}

Over two centuries of economic growth have put undeniable pressure on the ecological systems that underpin human well-being. While it is agreed that these pressures are increasing, views divide on how they may be alleviated. Some suggest technological advances will automatically keep us from transgressing key environmental thresholds; others that policy reform can reconcile economic and ecological goals; while a third school argues that only a fundamental shift in societal values can keep human demands within the Earth's ecological limits. Here we use novel integrated analysis of the energy-water-food nexus, rural land use (including biodiversity), material flows and climate change to explore whether mounting ecological pressures in Australia can be reversed, while the population grows and living standards improve. We show that, in the right circumstances, economic and environmental outcomes can be decoupled. Although economic growth is strong across all scenarios, environmental performance varies widely: pressures are projected to more than double, stabilize or fall markedly by 2050 . However, we find no evidence that decoupling will occur automatically. Nor do we find that a shift in societal values is required. Rather, extensions of current policies that mobilize technology and incentivize reduced pressure account for the majority of differences in environmental performance. Our results show that Australia can make great progress towards sustainable prosperity, if it chooses to do so.

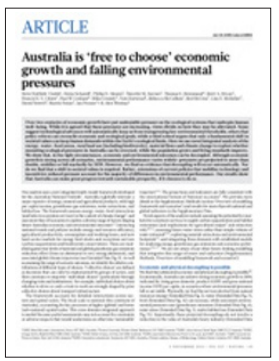

DETAILS

Citation: Nature 527, 49-53 (2015)

doi: $10.1038 /$ nature 16065

- RECEIVED 22 May 2015

- ACCEPTED 9 October 2015

- PUBLISHED ONLINE 4 November 2015

\section{SUMMARY}

Economic growth with environmental sustainability. An integrated modelling framework that accounts for climate, water, energy, materials, food, biodiversity and economic activity shows that it is possible for Australia to achieve sustainable prosperity - economic improvement without ecological deterioration - but that this requires specific economic and government policy choices to be made.

\section{The challenge}

Economic growth has many benefits, but in the past it has always damaged environmental systems and assets that are crucial for human wellbeing. Are these pressures inevitable? Can we increase income and economic activity while avoiding or repairing environmental damage? Can we decouple economic growth from greenhouse emissions, water stress, and loss of biodiversity?

Addressing these questions will be crucial for setting policies and framing constructive debate. Until now, providing well-based answers has not been easy, because we have lacked the data and models to test complex economic, social and physical interactions across multiple domains and issues. That is the challenge we set out to overcome. We focused on Australia as a globally relevant case study: it is a major producer of energy, and mineral and agricultural products, with high greenhouse-gas emissions, water extraction, and habitat loss.

\section{The discovery}

We have integrated nine different computer models - three global and six national - to test how private and public choices affect national income, living standards, and natural assets ${ }^{1-5}$. We modelled more than 20 potential combinations of choices, such as those concerning greenhouse-gas abatement, energy and resource efficiency, agricultural productivity, consumption, working hours, and markets for ecosystem services.

We found that Australia could dramatically reduce environmental pressures while enjoying strong economic growth. Across all scenarios, the value of economic activity is projected to grow more than tenfold from 1970 to 2050. At the same time, Australia could meet even the most stringent future targets for greenhouse-gas reductions, avoid increased water stress, and restore significant areas of native habitat.

We also found that reducing environmental pressures will not require a shift in societal values, but neither will it result automatically from technological advances and market forces. Instead, behavioural change - driven and supported by policy change - will be important (see Graphical abstract). Across our scenarios, 'top-down' collective choices (public policies) account for more than two-thirds of improvements in 
pure public-good outcomes (such as reductions in greenhouse emissions), by shaping household and enterprise behaviour. Top-down choices also account for more than half of improvements that involve a mix of public and private benefits (such as energy and water efficiencies, which financially benefit households and businesses). 'Bottom-up' individual choices are important, but are not sufficient.

\section{The implications}

Our findings imply that sound public policies are crucial to mobilizing appropriate technologies and uniting good economic performance with good environmental performance. Policy can also create economic advantages and harness new economic opportunities. However, because the interactions among different domains (food, energy, water, biodiversity and climate) are complex, the design and analysis of policy will need to be careful in order to harness synergies and avoid perverse outcomes.

One note of caution is that the most sustainable of our scenarios all occur in the context of stronger global action to address climate change (consistent with the Paris Agreement of December 2015). Although Australia could make great progress towards sustainability in a world taking less ambitious action, it would be harder ${ }^{6}$. The national economic benefits of reducing environmental pressures will be larger (and the costs smaller) in global settings that support sustainability, including a commitment to clean energy and healthy land and marine ecosystems.

A second note of caution is that although our modelling is world leading, it is far from perfect. We are engaging more deeply with public and private decision makers to better understand their needs, in order to inform and enable better national, regional and global decisions. For instance, we need better methods for exploring economic volatility, the social dimensions of industry and land-use transitions, and the complex global linkages between climate, weather, market settings, food production, food security, and social unrest ${ }^{7}$.

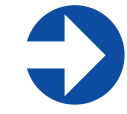

The full version of this article is at Nature's website at go.nature.com/28orqsm

\section{GRAPHICAL ABSTRACT}
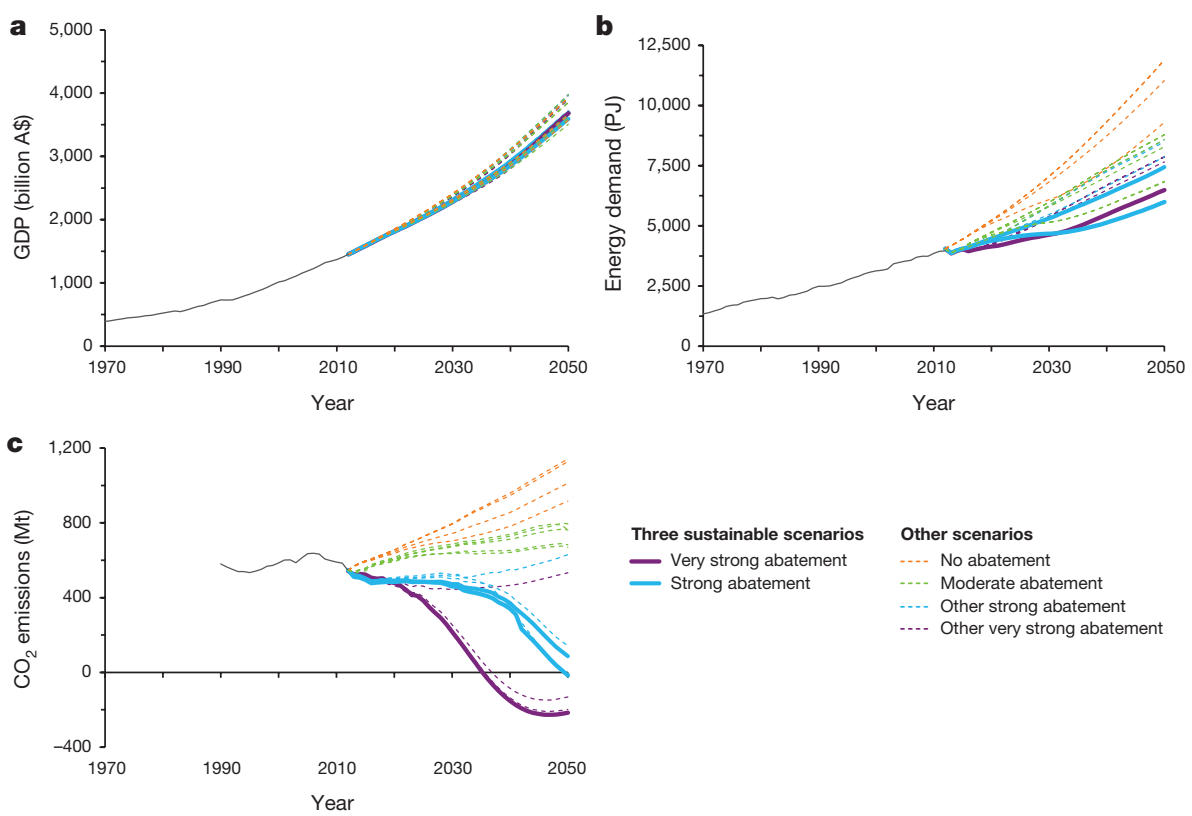

Projections of economic growth, energy demand and greenhouse-gas emissions in different scenarios. a, Gross domestic product (GDP) measures the market value of goods and services produced. Under all scenarios, whether 'sustainable' or otherwise, GDP is expected to increase by somewhere between $156 \%$ and $190 \%$. b, Energy demand is also predicted to increase, to a greater or lesser extent, in all scenarios. c, Greenhouse-gas emissions are predicted to fall under the sustainable scenarios but are expected to increase in other scenarios.

\section{FURTHER READING}

1. Bryan, B. A. et al. Land-use and sustainability under intersecting global change and domestic policy scenarios: trajectories for Australia to 2050. Global Env. Change 38, 130-152 (2016).

This article outlines the modelling framework for assessing national land-use trade-offs and synergies.

2. Cai, Y., Newth, D., Finnigan, J. \& Gunasekera, D. A hybrid energy-economy model for global integrated assessment of climate change, carbon mitigation and energy transformation. Appl. Energy 148, 381-395 (2015).

This outlines the global modelling framework used to establish four global scenarios.

3. Graham, P. W., Brinsmead, T. \& HatfieldDodds, S. Australian retail electricity prices: can we avoid repeating the rising trend of the past? Energy Policy 86, 456-469 (2015). This finds that lower transmission costs from better peak demand management outweigh the higher costs of low carbon electricity.

4. Grundy, M. J. et al. Scenarios for Australian agricultural production and land use to 2050 Agric. Syst. 142, 70-83 (2016).

This assesses agriculture in the context of different outlooks for national and global agricultural productivity.

5. Schandl, H. et al. Decoupling global environmental pressure and economic growth: scenarios for energy use, materials use and carbon emissions. J. Cleaner Prod. http://dx.doi.org/10.1016/j.jclepro.2015. 06.100 (2015)

This outlines global scenarios for resource and energy use and greenhouse emissions.

6. Walker, B. et al. Looming global-scale failures and missing institutions. Science $\mathbf{3 2 5}$, 1345-1346 (2009).

Explains how gaps in current national and international management approaches fail to address global environmental problems.

7. Lloyd's Food System Shock: The Insurance Impacts of Acute Disruption to Global Food Supply (Lloyd's, 2015); available at go.nature.com/28mwm8y This report explores the effects of plausible simultaneous shortfalls in food production.

\section{RELATED CONTENT}

Planetary boundaries: guiding human development on a changing planet W. Steffen et al. go.nature.com/28kknfn

Australian National Outlook 2015: Economic Activity, Resource Use, Environmental Performance and Living Standards, 1970-2050 S. Hatfield-Dodds et al. go.nature.com/28lkqpc

The material footprint of nations T. O. Wiedmann et al. go.nature.com/28m6qzr 